\title{
TEMPVAZ: Sistema para Estudo de Séries Temporais de Vazões de Rios Para o Planejamento da Operação de Sistemas Hidrotérmicos
}

\author{
Bruno F. Sousa Lucas S. M. Guedes \\ Rodney R. Saldanha \\ Programa de Pós-Graduação em Engenharia Elétrica - Universidade Federal de Minas Gerais \\ Av. Antônio Carlos 6627, 31270-901, Belo Horizonte, MG, Brasil \\ E-mail: brnfernan@gmail.com, lucasguedes1510@gmail.com, rodney@cpdee.ufmg.br
}

\begin{abstract}
RESUMO
As operadoras do setor elétrico sempre buscam técnicas capazes de otimizar o funcionamento, aumentar a confiabilidade e reduzir as perdas. As técnicas de previsão de séries temporais tem sido utilizadas em muitas aplicações do mundo real, como previsão do mercado financeiro, em utilitários de previsão de carga de meteorologia, previsão do estado do meio ambiente, previsão de confiabilidade entre outras aplicações. O planejamento da operação de um sistema de energia elétrica tem por objetivo determinar uma política de operação que atenda a demanda de energia elétrica de forma econômica e confiável. Este problema envolve um conjunto de usinas hidroelétricas visando estabelecer regras para determinar a turbinagem de cada reservatório de acordo com o volume de água presente no sistema e com os valores observados para as vazões afluentes. Neste trabalho será apresentado um estudo dos dados de vazões de rios, a fim de encontrar indicadores e padrões de ocorrência de chuvas, a partir do estudo das séries temporais de vazão de cada barragem considerada.

A maior parte dos sistemas de geração de energia existentes no Brasil são os chamados sistemas hidroelétricos. Estes sistemas são compostos por duas fontes geradoras de energia: as usinas hidrelétricas e as usinas termoelétricas. As usinas hidrelétricas são consideradas fontes de geração de energia limpa e apresentam baixo custo de produção. As usinas termoelétricas geram gases resultantes da queima de matéria prima e apresentam alto custo de produção. O processo de geração de energia em um sistema hidrotérmico é baseado em um planejamento dinâmico que envolve vários parâmetros, entre eles: a demanda da população, as estações do ano, as vazões dos rios (o foco desta pesquisa) entre outros.

Particularmente as vazões dos rios representam uma importante variável para alimentar o planejamento de execução de um sistema hidrotérmico. Os modelos matemáticos e os processos de geração de dados de séries temporais são geralmente complexos para estas aplicações e normalmente não são conhecidos a priori. Neste cenário, a utilização de técnicas lineares para construir o modelo de dados de uma série temporal, nem sempre é possível.

O objetivo geral deste trabalho é desenvolver uma ferramenta computacional capaz de estudar dados de vazões de rios e encontrar indicadores e padrões de ocorrência de chuvas, a partir do estudo das séries temporais de vazão de cada barragem considerada. Como objetivos específicos, com a ferramenta construída, espera-se gerar séries temporais de vazões futuras, dados importantes para alimentar o Planejamento Ótimo da Operação dos Sistemas Hidrotérmicos (POOSH) (da Silva et al., 2012).

Uma base de dados de 146 cascatas afluentes contendo 83 anos (1931 a 2014) de dados de chuvas foi utilizada. Uma pequena fatia de dados (5 anos inicialmente) é submetida a um algoritmo evolucionário que busca a solução de um problema multiobjetivo: uma aproximação não linear dos dados estudados. As soluções possíveis encontradas pelo algoritmo são transformadas em um conjunto de séries sintéticas para serem utilizadas em sistemas que buscam o planejamento ótimo da operação de sistemas hidrotérmicos.

A partir dos dados estudados durante o processo de otimização um estudo complementar paralelo é realizado para identificar padrões de ocorrências de chuvas visando identificação de cenários cíclicos no meio dos dados, este segundo estudo tem o objetivo de prever futuros cenários e identificar tendências, dados que podem ser utilizados na elaboração de condições de contorno para os problemas enfrentados durante o planejamento operacional
\end{abstract}


hidrotérmico. Os algoritmos implementados deram origem ao sistema TEMPVAZ que será apresentado neste trabalho.
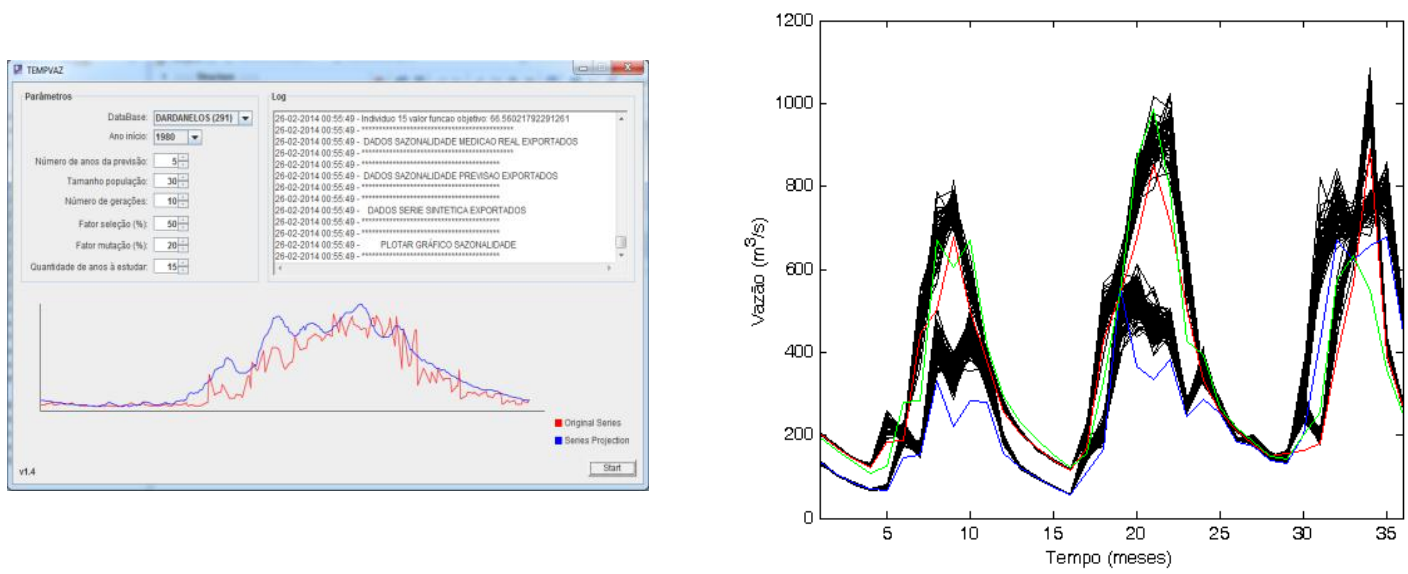

Figura 1: Tela inicial sistema TEMPVAZ e resultados

Na parte à esquerda da Figura 1 está apresentada a tela inicial do sistema, à direita estão apresentados um conjunto de resultados gerados pelo TEMPVAZ de uma previsão de 36 meses de vazão de chuvas da cabeceira da Usina 1 . As curvas em vermelho, azul e verde representam as vazões escolhidas como referência para alimentar o sistema, as curvas em preto representam um conjunto de 200 cenários factíveis gerados pelo sistema. Os resultados mostram que as curvas geradas pelo sistema são factíveis e que a sazonalidade respeita a tendência do grupo de dados estudados. Os cenários gerados são muito úteis para mapear as possibilidades de ocorrência de chuvas em um sistema hidrotérmico que é complexo e carece de planejamento operacional para manter os custos de geração de energia em níveis sustentáveis e viáveis.

A continuação desta pesquisa envolve a inclusão de novas funções objetivo no problema tal como indicativos de cenários futuros vindos dos operadores do setor elétrico, meteorologia, viés pessimista (ex. eventos naturais catastróficos) e a aplicação do problema em outros algoritmos de otimização não linear.

Palavras-chave: Séries Temporais, Otimização Sistemas Hidrotérmicos, Séries Sintéticas, Previsão de Vazões.

\section{Referências}

[1] Basharat, A.; Inc, K. \& Shah, M. (2009). Time series prediction by chaotic modeling of nonlinear dynamical systems. Computer Vision, 2009 IEEE 12th International Conference, pp. 1941 - 1948.

[2] Berard, A. \& Hebrail, G. (2013). Searching time series with hadoop in an electric power company. Em Proceedings of the 2nd International Workshop on Big Data, Streams and Heterogeneous Source Mining: Algorithms, Systems, Programming Models and Applications, BigMine '13, pp. 15--22, New York, NY, USA. ACM.

[3] Bohn, B. \& Griebel, M. (2013). An adaptive sparse grid approach for time series prediction. Em Sparse grids and applications, pp. 1--30. Springer.

[4] da Silva, D. A.; Bertolucci, L. H. B.; Andrade, M. G.; Costa, E. F. \& Soares, S. (2012). Programacao dinamica deterministica versus estocastica em um problema de planejamento da operacao de sistemas hidrotermicos. SBPO - Simposio Brasileiro de Pequisa Operacional. 